\title{
Local attitudes to the proposed translocation of blue sheep Pseudois nayaur to Sagarmatha National Park, Nepal
}

\author{
Jonathan H. Hanson, Maurice Schutgens, Rinzin P. Lama \\ Achyut Aryal and Maheshinar DhaKal
}

\begin{abstract}
Translocations are an important tool for the conservation of biodiversity, but although ecological feasibility studies are frequently conducted prior to implementation, social feasibility studies that consider how local communities perceive such projects are less common. The translocation of blue sheep Pseudois nayaur to Sagarmatha National Park, Nepal, has been proposed, to reduce livestock depredation by snow leopards Panthera uncia by providing an alternative prey base in addition to the small population of Himalayan thar Hemitragus jemlahicus. This study used systematic sampling, a quantitative questionnaire and qualitative interviews within the Park to provide data on the social viability of the proposed translocation. Quantitative analysis revealed moderate levels of support but qualitative analysis suggested that there are significant concerns about the proposal. In addition, multiple regression analysis found that women and livestock owners were significantly less supportive, although the model had low explanatory power. Potential crop damage and competition for forage were frequently cited as concerns, especially amongst those with a high level of dependence on natural resources. Given the mixed response to the proposed translocation of blue sheep to the Everest region, alleviating the reservations of local residents is likely to be key to any further consultation, planning or implementation.
\end{abstract}

Keywords Attitudes, blue sheep, human-wildlife conflict, Panthera uncia, Pseudois nayaur, Sagarmatha National Park, snow leopard, translocation

\footnotetext{
Jonathan H. Hanson ${ }^{*}$ (Corresponding author) Department of Geography, University of Cambridge, Cambridge, CB2 3EN, UK

E-mail jonnyhanson61@hotmail.com

Maurice Schutgens Space for Giants, Nanyuki, Kenya

RinZiN P. LAMA Workgroup on Endangered Species, J.F. Blumenbach Institute of Zoology and Anthropology, Georg-August University of Göttingen, Göttingen, Germany

Achyut ARYAL ${ }^{\dagger}$ Charles Perkins Centre, School of Life and Environmental Sciences, Faculty of Science, The University of Sydney, Sydney, Australia

Maheshwar DhaKal Department of National Parks and Wildlife Conservation, Kathmandu, Nepal

*Also at: Jubilee, 47b Glenarm road, Larne, BT40 1DT, UK

${ }^{\dagger}$ Also at: Department of Forest and Resource Management, Toi Ohomai Institute of Technology, Rotorua, New Zealand

Received 4 August 2017. Revision requested 2 October 2017.

Accepted 18 January 2018. First published online 5 November 2018.
}

Supplementary material for this article is available at https://doi.org/10.1017/So030605318000157

\section{Introduction}

lthough translocations are an important tool for the A conservation of biodiversity, less attention has been paid to their role in promoting human-wildlife coexistence. Unlike the term human-wildlife conflict, understandings of human-wildlife coexistence distinguish between impacts on humans caused by wildlife, and conflicts between humans over wildlife, typically between wildlife conservationists and those involved in alternative land uses (Marchini, 2014; Redpath et al., 2015; Mishra et al., 2016). Conflict scenarios frequently involve large mammals, especially carnivores (Ripple et al., 2014), and translocation has been suggested as a means to remove problem individuals and promote human-carnivore coexistence (Inskip \& Zimmerman, 2009; Treves et al., 2009). The translocation of prey species to reduce livestock depredation by predatory species, however, has received limited consideration.

In comparison to the biological and ecological aspects of conservation translocations, the socio-economic and political ramifications are poorly understood or have been neglected altogether (Armstrong \& Seddon, 2008), despite IUCN guidelines that promote social feasibility assessments as a necessary complement to biological assessments (IUCN/SSC, 2013). A number of studies, however, have explored these dimensions, including translocations of prairie dogs Cynomys spp. in the USA (Reading \& Kellert, 1993) and of European bison Bison bonasus in Lithuania (Balčiauskas \& Kazlauskas, 2014). Qualitative data can enhance such assessments (White et al., 2005), allowing insights into the varying factors that influence attitudes towards large mammals (Kansky \& Knight, 2014), and the intrinsic and extrinsic motivations that influence these attitudes (De Young, 1996; Richardson \& Loomis, 2009). Intrinsic motivations refer to reasons related to nature in and of itself, and extrinsic motivations refer more to the impacts of, or use of, nature, whether positive or negative.

In Sagarmatha National Park, Nepal, the translocation of a population of blue sheep Pseudois nayaur to increase the availability of wild prey and thus decrease the number of livestock depredations by snow leopards Panthera uncia 
has been suggested (Aryal et al., 2013; Ferretti et al., 2014). Snow leopards were believed to have been absent from the Park for 40 years (Ale et al., 2007), but have recolonized the area and now have a density of 1.8 per $100 \mathrm{~km}^{2}$ (DNPWC, 2013), similar to the neighbouring Qomolongma National Nature Reserve in Tibet (Chen et al., 2017). The Near Threatened Himalayan tahr Hemitragus jemlahicus is the primary prey species of the snow leopard but its low densities may be limiting the recovery of the snow leopard population within the Park, and contributing to household livestock losses (Lovari et al., 2009; Aryal et al., 2013).

Although the proposal to translocate blue sheep to ameliorate this situation has been based on a favourable habitat assessment (Aryal et al., 2013), a social feasibility assessment has not previously been conducted. The disputed presence of blue sheep historically in the Park further complicates the situation as the IUCN guidelines suggest particular caution be exercised when considering translocations of species new to an area (IUCN/SSC, 2013). Some sources have recorded historical blue sheep sightings in the area (Adhikari et al., 2013; Hillary \& Doig, 1962, cited in Lovari \& Mishra, 2016) but others argue against its historical distribution locally (S. Ale, pers comm.). The species has been recorded historically in the neighbouring Rolwaling Conservation Area but not in recent times (Ale et al., 2010).

This study was designed to address the various components of a social feasibility assessment for conservation translocation (IUCN/SSC, 2013), utilizing the Sustainable Livelihoods Framework (Chambers \& Conway, 1992; Scoones, 1998), which assesses how households access a range of tangible and intangible assets to create a livelihood and manage associated risks. The study posed the following three questions: What are local attitudes to the proposed blue sheep translocation? What factors best explain these attitudes? What are the motivations behind local attitudes?

\section{Study area}

Sagarmatha National Park (Fig. 1) was gazetted in 1976, with a later buffer zone introduced in 2002. Habitat gradients exist between permanent snow at $8,848 \mathrm{~m}$ and temperate oak and pine forests at 2,845 $\mathrm{m}$ (Bhuju et al., 2007), with snow leopard habitat characterised by subalpine and alpine vegetation at 3,500-5,500 $\mathrm{m}$. According to the most recent census, 3,500 people permanently live in 63 settlements within the Park, with an overall population density of 0.33 people $/ \mathrm{km}^{2}$ (Government of Nepal, 2012). Residents are mostly engaged in a combination of agro-pastoralism and tourism for their livelihoods and a centralised conservation governance regime is in place in the Park, with some local devolution following the introduction of the buffer zone (Bhuju et al., 2007).

\section{Methods}

\section{Questionnaires}

A household questionnaire (Supplementary Material 1) was developed, with both closed and open questions (White et al., 2005); potential explanatory variables were included, based on a systematic literature review. Alongside typical demographic factors a livelihoods index based on the Sustainable Livelihoods Framework (DFID, 1999; Steimann, 2005), with a potential range of $0-1$, was included, as were measures of attitudes to snow leopards and snow leopard conservation measured on five-point Likert scales $(\mathrm{JHH}$, unpubl. data). A summative attitudinal scale, using a fivepoint Likert scale, was employed to measure attitudes to the proposed translocation. Questions involving identification of blue sheep and snow leopards used colour photographs of similar-sized herbivores and carnivores present in the study site or in similar protected areas in Nepal (Wildscreen, 2014). The draft household questionnaire was first piloted with a sample of 24 households outside the Park.

Questionnaire data were collected from 260 individuals in the Park during February-March 2014, by two Nepali research assistants, in either English or Nepali. Systematic sampling was used because of the informal nature of many of the settlements and the absence of a sampling frame. Every fourth house in each settlement was sampled, an approach similar to studies elsewhere in Nepal (Paudel \& Thapa, 2001). To promote and ensure reliability, random back-checking of $10 \%$ of surveys was conducted (White et al., 2005). Respondents unfamiliar with blue sheep, or unable to identify it from the photograph, were shown the correct image and given a description of the species before proceeding.

Following trends in recent analyses of attitudes to the snow leopard (Suryawanshi et al., 2014; Alexander et al., 2015), the attitudinal scales used were all treated as continuous data. Based on this approach, the regression models were therefore used for explanation rather than prediction (Mac Nally, 2000). Data for household livestock owned and household livestock lost to snow leopards were transformed to a logio scale before inferential analysis, following Zimmermann et al. (2005). Inter-observer and inter-coder reliability were both tested, using paired sample $t$ tests (Sakurai et al., 2013). Cronbach's alpha test score for the blue sheep translocation attitudinal scale was 0.954 , indicating a high degree of reliability.

A multiple regression model was used to explore the variables that best explained attitudes towards blue sheep translocation. Data were checked to ensure they met the necessary assumptions for multiple regression models (Field, 2013). Hierarchical entry based on theoretical suitability was used and model selection used the $R^{2}$ change results to determine goodness-of-fit (Mac Nally, 2000). P-P plots 


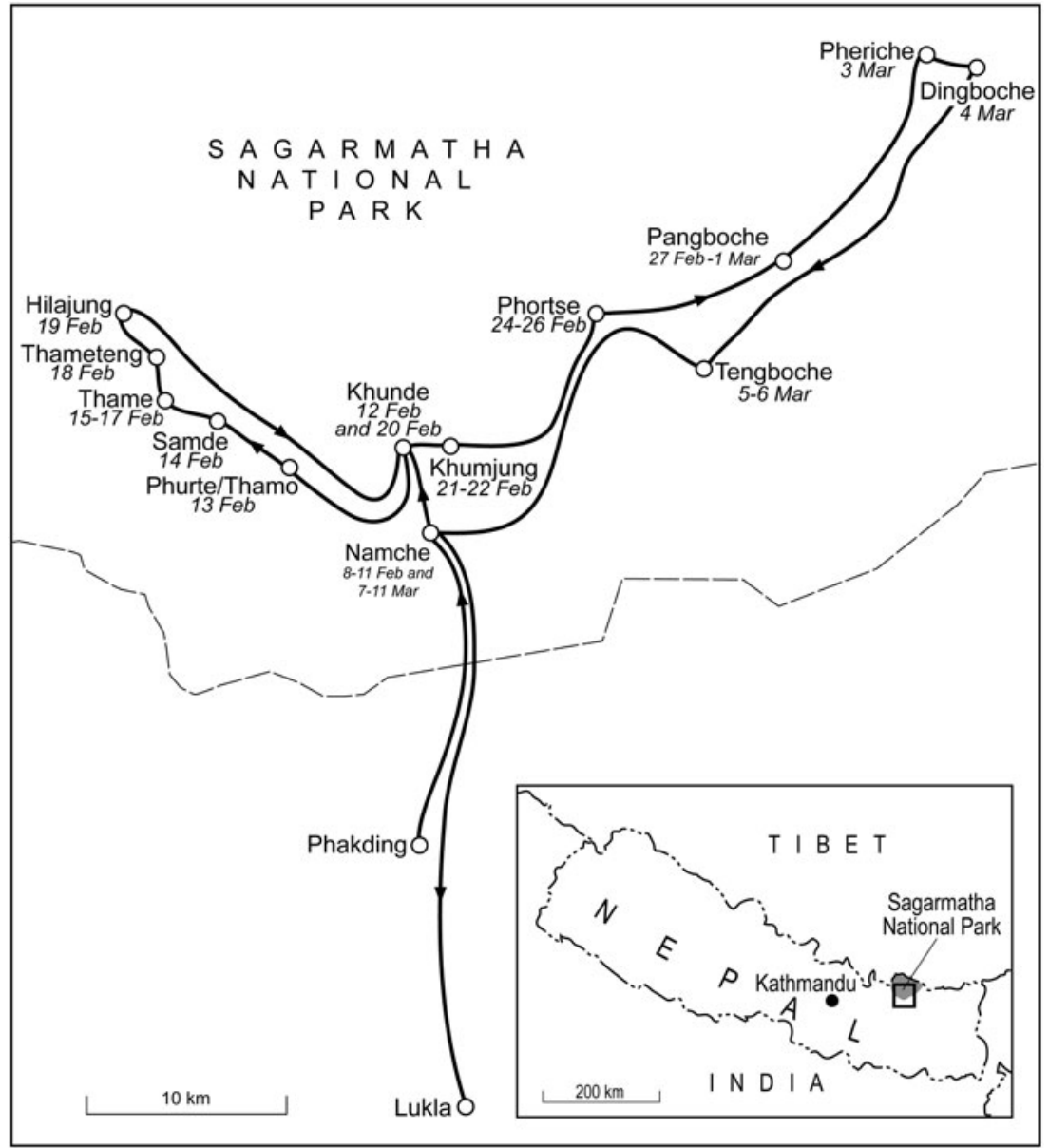

FIG. 1 Sagarmatha National Park, showing sampling locations and dates in 2014 on which respondents' attitudes to the proposed translocation of blue sheep Pseudois nayaur were assessed. to test for normality in multiple regression models indicated some evidence of non-normality in the dependent variable, and bootstrapping was therefore used for the final model (Field, 2013).

\section{Interviews}

The focus of the semi-structured interviews was to provide concurrent, cross-method triangulation with the questionnaire data by interviewing key informants (Mikkelsen, 2005). The questions followed the outline of the household survey, and interview sampling followed the framework developed for the household questionnaires, with the aim of collecting $10 \%$ of the number of surveys administered. Twenty-six interviews were conducted and there was a bias in the sample towards community and conservation leaders, with Buddhist monks, teachers and women's group leaders being the next three most numerous groups. The interviews were usually administered in Nepali by a research assistant, with either JHH or MS present. A small number of interviewees agreed to be interviewed in English. After transcription, the interview data were analysed both quantitatively and qualitatively to triangulate and complement the questionnaire analysis.

\section{Results}

The majority of questionnaire respondents were previously unfamiliar with blue sheep (73.1\%) and were unable to positively identify it from a photograph (76.5\%). When asked whether translocating a new prey species to the area would reduce livestock depredation by snow leopards, 10\% completely agreed, $35.4 \%$ agreed, $41.5 \%$ were neutral, $12.3 \%$ disagreed and $0.8 \%$ completely disagreed. On being asked whether a population of blue sheep should be translocated to the Park, $13.5 \%$ completely agreed, $49.2 \%$ agreed, $\mathbf{2 2 . 7} \%$ were neutral, $\mathbf{1 3 . 5} \%$ disagreed and $\mathbf{1 . 1} \%$ completely disagreed. The Likert scale results from these two questions were scored and combined to create the blue sheep translocation attitudinal scale, with a mean of $3.51 \pm$ SD 0.82 . Triangulation interviews, however, showed reduced levels of support for translocation, with slightly higher levels of neutral sentiment, and a lower proportion agreeing with the idea (Table 1).

\section{Explaining local attitudes}

In the multiple regression model (Table 2) two variables best explained attitudes to the proposed blue sheep translocation. 
TABLE 1 Key informant attitudes to proposed blue sheep Pseudois nayaur translocation in Sagarmatha National Park.

\begin{tabular}{lrr}
\hline Question/response & $\mathrm{N}$ & $\%$ \\
\hline Support for proposed blue sheep translocation & & \\
Yes & 11 & 42.3 \\
Maybe & 10 & 38.5 \\
No & 5 & 19.2 \\
Total & 26 & 100.0 \\
Reason(s) for opinion on proposed blue sheep translocation \\
No reason & 5 & 19.2 \\
Positive intrinsic reason & 8 & 30.8 \\
Positive extrinsic reason & 0 & 0.0 \\
Negative reason & 4 & 15.4 \\
More than 1 positive reason & 2 & 7.7 \\
Positive \& negative reasons & 7 & 26.9 \\
Total & 26 & 100.0 \\
\hline
\end{tabular}

Gender made the single biggest contribution, with women being significantly less positive than men. The only other significant predictor was total livestock owned per household, which had a negative relationship with attitudes to blue sheep translocation. Age and education were included in the model but did not make significant contributions. The model had low explanatory power overall $\left(R^{2}=0.096\right)$, suggesting that factors not considered in the study are likely to be influential. In addition, a number of variables excluded from the model had significant relationships in univariate analysis. Those with more education $(r=0.036, \mathrm{P}=0.002)$, who were younger $(r=-0.007, \mathrm{P}=0.024)$, who were less than 'very religious' $(t=3.04, \mathrm{P}=0.009)$ and who were more positive towards snow leopard conservation $(r=0.15$, $\mathrm{P}=0.005$ ), were all significantly more positive towards the translocation of blue sheep.

\section{Motivations behind local attitudes}

A range of motivations were given for questionnaire and interview respondents' attitudes to the proposed translocation (Fig. 2). Approximately one third of questionnaire respondents gave a positive intrinsic reason, such as cultural or religious beliefs. Positive comments also related to the tourism potential of having blue sheep in the area, with one respondent stating that 'For the tourism aspect it's good as people might come to see the animal' (microcredit cooperative officer). The potential of the translocation to reduce livestock depredation by snow leopards was also voiced: 'As the snow leopard's preferred prey, it may help to reduce livestock losses if its population is growing well. Also it's good to have a new animal in our valley' (teacher).

Negative reasons were the next most common motivator and were corroborated by triangulation interviews (Table 1). Of those who provided negative reasons in questionnaires and interviews, potential crop damage was a common concern: 'If the blue sheep don't cause damage the way the Himalayan thar does, then it would be good to have it. Otherwise there is no use to bring such a species' (conservation leader); 'If it also destroys the crops in the way the thar do then it's not good to translocate it. ..In that case people won't accept blue sheep here' (youth leader).

Additional concerns included whether the species was native to the area and whether the blue sheep translocation would detract from other conservation activities: 'We should focus on conserving the species here and the blue sheep in its own habitat. Introducing it will hamper the conservation of other species here' (teacher) and 'Instead of artificial conservation with blue sheep we would be better to think of ways to increase the number of tahr' (conservation leader).

\section{Further questionnaire information}

The mean age of respondents was 41 years (range 16-86). Years of education were $0-15$, with a mean of 4 . Of those surveyed $56.9 \%$ were men and $43.1 \%$ women, and the majority of respondents were local (83.6\%) rather than non-local (16.5\%). Most of those surveyed were Buddhist (87.3\%), and the remainder were classed as 'other' (12.7\%) with respect to their religious beliefs. With the five-point Likert scale used to measure religiosity, there was a lack of data for categories three to five and these were collapsed into category two. Less than 'very religious' respondents therefore comprised $49.2 \%$ of those surveyed and the very religious $50.8 \%$. Finally, $41.9 \%$ of respondents were able to positively identify a snow leopard.

TABLE 2 Linear model exploring attitudes to proposed blue sheep translocation in Sagarmatha National Park $\left(\mathrm{N}=260, R^{2}=0.096\right.$; this model had the highest significant $R^{2}$ change score (0.040, $\mathrm{P}<0.001$ ) of the six models tested).

\begin{tabular}{|c|c|c|c|c|}
\hline Explanatory variable & $b(95 \% \mathrm{CI})^{1}$ & $\mathrm{SE}^{1}$ & Standardized $b$ & $\mathrm{P}$ \\
\hline Constant & $3.97(3.58-4.34)$ & 0.21 & & 0.001 \\
\hline Number of years of education & $0.009(-0.019-0.038)$ & 0.014 & 0.046 & 0.54 \\
\hline Age & $-0.005(-0.012-0.002)$ & 0.004 & -0.10 & 0.14 \\
\hline Number of household livestock (log10 scale) & $-0.24(-0.44--0.053)$ & 0.097 & -0.14 & 0.013 \\
\hline Gender $^{2}$ & $-0.36(-0.56--0.17)$ & 0.10 & -0.22 & 0.001 \\
\hline
\end{tabular}

${ }^{1} 95 \%$ bias corrected and and standard errors are based on 1,00o bootstrap samples.

${ }^{2} \mathrm{O}$, male; 1 , female. 


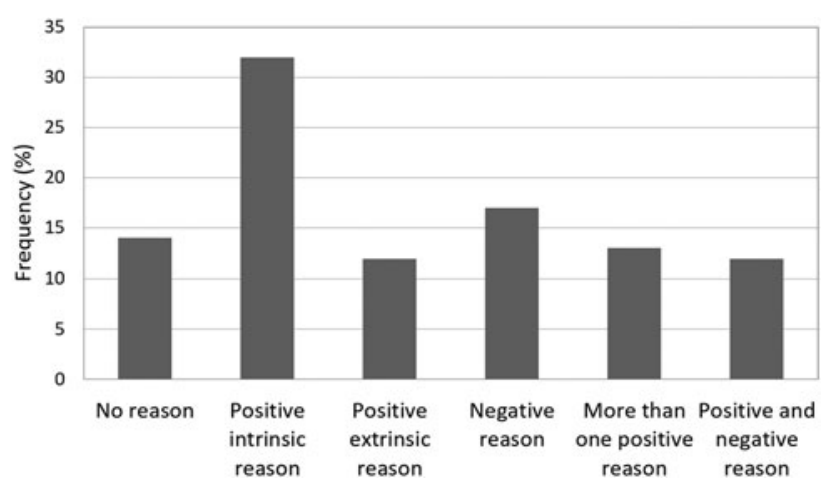

Fig. 2 Reasons given by 260 questionnaire respondents for their attitudes towards proposed blue sheep translocation.

The mean attitude score towards snow leopards was $3.57 \pm \mathrm{SD} 0.97$ and the mean attitude score towards snow leopard conservation was $3.98 \pm \mathrm{SD}$ 0.39. A number of respondent attributes were also considered at the household level. The mean Sustainable Livelihoods Index score was $0.53 \pm$ SD 0.12, mean number of livestock owned per household was $5.43 \pm$ SD 9.04, and mean self-reported livestock losses to snow leopards in the previous 12 months were $0.26 \pm$ SD 0.60 per household (range $0-9$ ).

\section{Discussion}

The ecological viability of translocating a species into an area is often the sole consideration of a study, with the socio-economic impacts regularly overlooked (Armstrong \& Seddon, 2008). This is true of earlier research on the potential translocation of blue sheep to the Park (Aryal et al., 2013), which considered only the ecological viability of the proposal. Yet participation and consultation have been identified as critical factors in the success of human-carnivore coexistence projects (Treves et al., 2009), and we therefore aimed to explore local attitudes towards the proposed translocation. Questionnaire data from our social viability assessment showed moderate levels of support for the reintroduction of blue sheep to Sagarmatha National Park, with $62.7 \%$ 'agreeing' or 'completely agreeing' with the idea. However, the more nuanced and critical reflections apparent in the triangulation interviews suggest that these data may overlook some of the local residents' reservations about the proposal. Data from the interviews also affirmed the importance of probing depth of knowledge, rather than just breadth of knowledge, in questionnaire research for conservation (White et al., 2005).

\section{Explaining local attitudes}

The significance of gender in explaining attitudes in this study has not been universally matched elsewhere in attitudes towards conservation translocations, although it has proved significant in explaining attitudes towards snow leopards (Suryawanshi et al., 2014; Alexander et al., 2015). Although women were less positive towards reintroduced European bison in Lithuania (Balčiauskas \& Kazlauskas, 2014), men were less positive towards the idea of wolf reintroductions in North America and Europe than women (Williams et al., 2002). However, gender was ranked as the fifth and fourth most important predictor in these studies, respectively. The difference in our study may be the developing-world context, where women are often more involved in, and dependent on, resource extraction, including agropastoralism, than men and are therefore more likely to display negative attitudes towards perceived threats to such activities (Alexander et al., 2015).

Total livestock owned per household was the other significant explanatory factor in the regression model, and had a negative relationship with attitudes to blue sheep translocation. Although the justification for the proposed translocation of blue sheep to the Park has been to reduce livestock depredation by increasing wild prey availability for snow leopards (Aryal et al., 2013; Ferretti et al., 2014; Lovari \& Mishra, 2016), these findings suggest that it is those people most likely to benefit from the proposal who may be amongst those most opposed. Fears over competition for forage, as well as crop and livestock losses, may drive this perspective, as found elsewhere with black-footed ferrets Mustela nigripes and praire dogs in the USA and blue sheep in China (Reading \& Kellert, 1993; Alexander et al., 2015).

\section{Motivations behind local attitudes}

The motivations for attitudes to the proposed translocation were more nuanced and critical than the attitudes themselves, with more respondents giving negative, or mixed positive and negative reasons, as is common in other contexts (De Young, 1996; Richardson \& Loomis, 2009). The triangulation interviews provided additional context and rationale for local perspectives. Of those who had negative or mixed attitudes and motivations, potential crop damage was the most common concern, as it represents a clear threat to local livelihoods (Chambers \& Conway, 1992; Scoones, 1998). This is consistent with research on blue sheep in China (Alexander et al., 2015) and with prairie dogs in the USA (Reading \& Kellert, 1993).

\section{Conclusion}

This study has indicated there are mixed levels of support for blue sheep translocation. However, the low explanatory power of the model limits the extrapolations and inferences that can be made. Future studies should consider a wider number of potential explanatory variables in regression modelling. In addition, concern over whether blue sheep 
are native to the Park, and whether translocation would prove a distraction from existing conservation efforts for other species, was the second most common issue raised in the triangulation interviews. This reflects the ongoing debate about whether blue sheep are, in fact, native to the area, with conflicting opinions between published sources (Adhikari et al., 2013; Aryal et al., 2013; Hillary \& Doig, 1962, cited in Lovari \& Mishra, 2016) and expert opinion (S. Ale, pers comm.). Alleviating the concerns of local residents about the historical presence and potential impacts of blue sheep is likely to be key to any further planning or implementation regarding the translocation of the species to the Park. Given this, we recommend further research and consultation on the proposal.

Acknowledgements We thank all the residents of Sagarmatha National Park who took part in our surveys, Niki Shrestha for additional research assistance and Phil Stickler for creating the map. JHH was supported by the Economic and Social Research Council grant ES/ J500033/1. We are grateful to the Department of National Parks and Wildlife Conservation for permission to conduct our fieldwork in the Everest area.

Author contributions Conceptualization of study and methods: $\mathrm{JHH}$ and AA; funding acquisition and data analysis: JHH; fieldwork and initial writing: JHH, MS and RPL; revision and editing: AA and MD. All authors approved the final version for submission.

\section{Conflicts of interest None.}

Ethical standards This research complies with the journal's Code of Conduct for authors. Ethical approval was provided by the Department of Geography's Ethics Review Group at the University of Cambridge.

\section{References}

Adhikari, D., Shrestha, D., Routh, K. \& Shrestha, U.K. (2013) Everest Base Camp. Nepal Map Publisher, Kathmandu, Nepal.

Ale, S.B., Thapa, K., Jackson, R. \& David Smith, J.L. (2010) The fate of snow leopards in and around Mt. Everest. Cat News, 53, 19-21.

Ale, S.B., Yonzon, P. \& Thapa, K. (2007) Recovery of snow leopard Uncia uncia in Sagarmatha (Mount Everest) National Park, Nepal. Oryx, 41, 89-92.

Alexander, J., Chen, P., Damerell, P., Youkui, W., Hughes, J., SHI, K. \& Riordan, P. (2015) Human wildlife conflict involving large carnivores in Qilianshan, China and the minimal paw-print of snow leopards. Biological Conservation, 187, 1-9.

Armstrong, D.P. \& SEDdon, P.J. (2008) Directions in reintroduction biology. Trends in Ecology \& Evolution, 23, 20-25.

Aryal, A., Brunton, D. \& Raubenheimer, D. (2013) Habitat assessment for the translocation of blue sheep to maintain a viable snow leopard population in the Mt Everest Region, Nepal. Zoology and Ecology, 23, 1-17.

Balčiauskas, L. \& Kazlauskas, M. (2014) Forty years after reintroduction in a suboptimal landscape: public attitudes towards European bison. European Journal of Wildlife Research, 60, 155-158.
Bhuju, U.R., Shakya, P.R., Basnet, T.B. \& Shrestha, S. (2007) Nepal Biodiversity Resource Book: Protected Areas, Ramsar Sites and World Heritage Sites. International Centre for Integrated Mountain Development and the Ministry of Environment, Science and Technology, Kathmandu, Nepal.

Chambers, R. \& Conway, G.R. (1992) Sustainable Rural Livelihoods: Practical Concepts for the 21st Century. Institute of Development Studies, Brighton, UK.

Chen, P., GaO, Y., Wang, J., Pu, Q., Lhaba, C., Hu, H. et al. (2017) Status and conservation of the Endangered snow leopard Panthera uncia in the Qomolangma National Nature Reserve, Tibet. Oryx, 51, 590-593.

De Young, R. (1996) Some psychological aspects of reduced consumption behavior: The role of intrinsic satisfaction and competence motivation. Environment and Behavior, 28, 358-409.

DFID (1999) Sustainable Livelihoods Guidance Sheets. Department for International Development, London, UK.

DNPWC (2013) Snow Leopard Conservation Action Plan for Nepal 2005-2015 (Revised 2012). Department of National Parks and Wildlife Conservation, Kathmandu, Nepal.

Ferretti, F., Lovari, S., Minder, I. \& Pellizzi, B. (2014) Recovery of the snow leopard in Sagarmatha (Mt. Everest) National Park: effects on main prey. European Journal of Wildlife Research, 60, 559-562.

FIELD, A. (2013) Discovering Statistics Using IBM SPSS Statistics. 5th edition. Sage, London, UK and New York, USA.

Government of Nepal (2012) National Population and Housing Census 2011: Village Development Committee/Municipality. Central Bureau of Statistics, Kathmandu, Nepal.

Hilary, E. \& Doig, D. (1962) High in the Thin Cold Air. Hodder and Stoughton, Wellington, New Zealand.

Inskip, C. \& Zimmerman, A. (2009) Human-felid conflict: a review of patterns and priorities worldwide. Oryx, 43, 18-34.

IUCN/SSC (2013) Guidelines for Reintroductions and Other Conservation Translocations. Version 1. IUCN Species Survival Commission, Gland, Switzerland.

Kansky, R. \& Knight, A.T. (2014) Key factors driving attitudes towards large mammals in conflict with humans. Biological Conservation, 179, 93-105.

Lovari, S., Boesi, R., Minder, I., Mucci, N., Randi, E., Dematteis, A. \& ALE, S.B. (2009) Restoring a keystone predator may endanger a prey species in a human-altered ecosystem: the return of the snow leopard to Sagarmatha National Park. Animal Conservation, 12, 559570.

LOVARI, S. \& Mishra, C. (2016) Living on the edge: depletion of wild prey and survival of the snow leopard. In Snow Leopards (eds T. McCarthy \& D. Mallon), pp. 69-76. Academic Press, London, UK and New York, USA.

Mac Nally, R. (2000) Regression and model-building in conservation biology, biogeography and ecology: the distinction between - and reconciliation of - 'predictive' and 'explanatory' models. Biodiversity \& Conservation, 9, 655-671.

MARCHINI, S. (2014) Who's in conflict with whom? Human dimensions of the conflicts involving wildlife. In Applied Ecology and Human Dimensions in Biological Conservation (eds L.M. Verdade, M. Lyra-Jorge \& C.I. Piña), pp. 189-209. Springer, London, UK.

Mik kelsen, B. (2005) Methods for Development Work and Research: A New Guide for Practitioners. Sage, London, UK and New York, USA.

Mishra, C., Redpath, S.R. \& Suryawanshi, K.R. (2016) Livestock predation by snow leopards: conflicts and the search for solutions. In Snow Leopards (eds T. McCarthy \& D. Mallon), pp. 59-67. Academic Press, London, UK and New York, USA.

PAudel, G.S. \& ThaPA, G.B. (2001) Changing farmers' land management practices in the hills of Nepal. Environmental Management, 28, 789-803. 
Reading, R.P. \& Kellert, S.R. (1993) Attitudes toward a proposed reintroduction of black-footed ferrets (Mustela nigripes).

Conservation Biology, 7, 569-580.

Redpath, S.M., Bhatia, S. \& Young, J. (2015) Tilting at wildlife: reconsidering human-wildlife conflict. Oryx, 49, 222-225.

Richardson, L. \& Loomis, J. (2009) The total economic value of threatened, endangered and rare species: an updated meta-analysis. Ecological Economics, 68, 1535-1548.

Ripple, W.J., Estes, J.A., Beschta, R.L., Wilmers, C.C., Ritchie, E. G., Hebblewhite, M. et al. (2014) Status and ecological effects of the world's largest carnivores. Science, 343, 151.

SaKurai, R., Jacobson, S.K. \& Carlton, J.S. (2013) Media coverage of management of the black bear Ursus thibetanus in Japan. Oryx, $47,519-525$.

Scoones, I. (1998) Sustainable Rural Livelihoods: A Framework for Analysis. Institute of Development Studies, Brighton, UK.

Steimann, B. (2005) Livelihood strategies in North West Pakistan: NCCR IP6 Working Paper No. 5. National Centre of Competence in Research, Zurich, Switzerland.
Suryawanshi, K.R., Bhatia, S., Bhatnagar, Y.V., Redpath, S. \& Mishra, C. (2014) Multiscale factors affecting human attitudes toward snow leopards and wolves. Conservation Biology, 28, 1657-1666.

Treves, A., Wallace, R.B. \& White, S. (2009) Participatory planning of interventions to mitigate human-wildlife conflicts. Conservation Biology, 23, 1577-1587.

White, P.C.L., Jennings, N.V., Renwick, A.R. \& Barker, N.H.L. (2005) Questionnaires in ecology: a review of past use and recommendations for best practice. Journal of Applied Ecology, 42, 421-430.

WildSCREEN (2014) Arkive-discover the world's most endangered species. Wildscreen Arkive. Http://www.arkive.org/ [accessed 2 February 2014].

Williams, C.K., Ericsson, G. \& Heberlein, T.A. (2002) A quantitative summary of attitudes toward wolves and their reintroduction (1972-2000). Wildife Society Bulletin, 30, 575-584.

Zimmermann, A., Walpole, M.J. \& Leader-Williams, N. (2005) Cattle ranchers' attitudes to conflicts with jaguar Panthera onca in the Pantanal of Brazil. Oryx, 39, 406-412. 